Article

\title{
Podophyllotoxin-Loaded Nanostructured Lipid Carriers for Skin Targeting: In Vitro and In Vivo Studies
}

\author{
Jihui Zhao ${ }^{\dagger}$, Xianghua Piao ${ }^{\dagger}$, Xiaoqin Shi, Aiyong Si, Yongtai Zhang and Nianping Feng * \\ School of Pharmacy, Shanghai University of Traditional Chinese Medicine, Shanghai 201203, China; \\ zhaojihui07168@163.com (J.Z.); piaoxianghua721@126.com (X.P.); xiaoqin_shi87@163.com (X.S.); \\ giantison@163.com (A.S.); analysisdrug@126.com (Y.Z.) \\ * Correspondence: npfeng@hotmail.com; Tel./Fax: +86-21-51322198 \\ + These authors contribute equally to this work. \\ Academic Editor: Diego Muñoz-Torrero \\ Received: 27 September 2016; Accepted: 7 November 2016; Published: 17 November 2016
}

\begin{abstract}
Nanostructured lipid carriers (NLC) exhibit high skin targeting efficiency and good safety. They are promising vehicles for topical drug delivery. This study aims to increase the skin distribution of podophyllotoxin (POD) by incorporating it into NLCs. Two kinds of POD-loaded NLCs

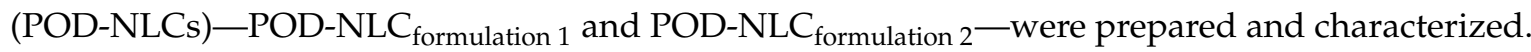
Their skin targeting efficiencies were compared by conducting in vitro and in vivo experiments. Obviously smaller mean particle size was observed for POD-NLC formulation $1_{1}(106 \mathrm{~nm})$ than POD-NLC formulation $2_{2}(219 \mathrm{~nm})$, whereas relatively low POD loadings (less than $0.5 \%$ ) were observed for both POD-NLC $\mathrm{formulation} 1_{1}(0.33 \%)$ and POD-NLC formulation $2(0.49 \%)$. Significantly higher in vitro and in vivo rat skin deposit amounts of POD $(p<0.01)$ were detected after the topical application of POD-NLC $\mathrm{formulation} 1_{\text {compared to POD-NLC }}$ formulation 2. To visualize the skin distribution behavior of hydrophobic active pharmaceutical ingredients (APIs) when NLCs were used as carriers, POD was replaced with Nile red (NR-a hydrophobic fluorescent probe), and the distribution behavior

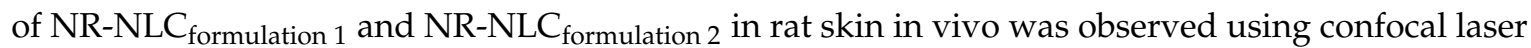
scanning microscopy (CLSM). Higher fluorescent intensity was observed in rat skin after the topical application of NR-NLC $\mathrm{C}_{\text {formulation } 1}$ than NR-NLC $\mathrm{C}_{\text {formulation 2, suggesting that higher skin targeting }}$ efficiency might be obtained when NLCs with smaller mean particle size were used as carriers for hydrophobic APIs. This result was in accordance with those of skin distribution evaluation

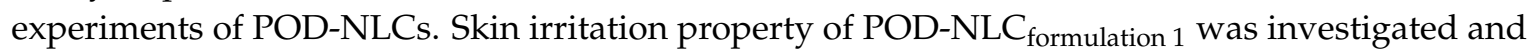
no irritation was observed in intact or damaged rabbit skin, suggesting it is safe for topical use. Our results validated the safety of NLCs when applied topically. More importantly, mean particle size might be an important parameter for formulation optimization when NLCs are used as carriers for hydrophobic APIs for topical application, considering that their loading is relatively low.
\end{abstract}

Keywords: podophyllotoxin; nanostructured lipid carriers; skin targeting efficiency

\section{Introduction}

In the treatment of skin diseases, the efficacy of topical drugs depends on their ability to reach the desired site of action (specific skin layers) and remain at the site in an effective concentration for the appropriate time. Drug safety depends critically on the tight control of release rate and target specificity by the delivery vehicle. However, conventional topical formulations, such as solutions, ointments, and gels are characterized by indiscriminate skin targeting properties and rapid drug release. When these vehicles are employed as carriers, topical drugs such as triamcinolone, $5 \alpha$-dihydrotestosterone, and tretinoin exhibit poor therapeutic effects, as well as mild to severe local and systemic adverse 
reactions [1-3]. The development of novel drug delivery systems that control both target specificity and drug release rates is urgently needed in the dermatological field.

Liposomes were first described by Bangham and co-workers in the 1960s [4]. Liposomes can encapsulate both hydrophilic and lipophilic drugs, and were first used for systemic and then topical drug delivery. When used as topical carriers, liposomes can confer skin targeting and prolonged temporal release properties of the loaded drug. They can also act to reduce topical and systemic adverse reactions, because their small particle size enables close contact with the superficial junctions of corneocyte clusters and furrows between corneocyte islands. The similarities between liposome components and epidermal lipids promote lipid exchange and facilitate penetration of the loaded drug through the stratum corneum to deeper skin layers, where the drug is deposited $[5,6]$. Liposomes have been used as carriers for many topical drugs; e.g., corticosteroids, retinoids, and local anesthetics [7]. However, the main drawback of liposomes as drug carriers is their poor physical stability—namely, drug leakage during storage.

Solid lipid nanoparticles (SLNs) — the first generation of lipid nanoparticles—are composed of lipids that are solid at room temperature and which are covered by a surfactant shell that stabilizes their dispersion. The first SLNs were developed in the early 1990s. SLNs are considered to have all the advantages of liposomes when used as topical carriers, and can also improve the physical and chemical stability of loaded drugs [8,9]. SLNs have been used as topical carriers for many lipophilic drugs, such as isotretinoin, retinyl palmitate, prednicarbate, tacrolimus, penciclovir, clotrimazole, and antioxidants including lutein, curcuminoids, quercetin, and idebenone [10-19].

Condyloma accuminata (CA) is one of the most common sexually transmitted diseases. Podophyllotoxin (POD, an antimitotic agent), can destroy warts by inducing tissue necrosis and has been recommended by the World Health Organization (WHO) as the first line drug for the treatment of CA [20]. The chemical structure of POD is shown in Figure 1. However, the efficacy of $0.5 \%$ POD tincture and cream against CA is considerably compromised by a high recurrence rate (approximately $40 \%$ ), skin irritation, and possible systemic toxicity [21-23].

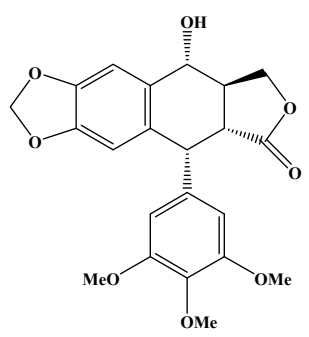

Figure 1. Chemical structure of podophyllotoxin (POD).

Chen et al. prepared and compared two $0.15 \%$ POD-loaded SLNs with different mean particle sizes [24]. Neither SLN enabled the systemic absorption of POD, and the SLN with the smaller mean particle size exhibited higher epidermal targeting efficiency than a $0.15 \%$ POD tincture. These data suggest that SLNs are a promising carrier for the topical delivery of POD. However, the POD content in SLNs is approximately one third of that in the available tinctures or creams, which could compromise its therapeutic efficiency against CA. POD-loaded SLNs may also exhibit a serious physical stability problem; namely, drug expulsion during storage [25].

Nanostructured lipid carriers (NLCs, the second generation of lipid nanoparticles), are mixtures of solid and fluid lipids. The fluid lipid phase is thought to be embedded in the solid lipid matrix or to be localized at the interphase of the solid platelets and the surface layer. The introduction of fluid lipids still allows the lipid nanoparticles to remain in a solid state at room temperature, but the crystal lattice in the lipid particles becomes somewhat imperfect, improving both drug loading capacity and physical stability [26]. NLCs have been used as topical carrier for many drugs, such as acitretin, non-steroidal anti-inflammatory drugs (NSAIDs; ketoprofen, indomethacin), antioxidants 
(lutein, CoQ10), flubiprofen, clotrimazole, and celecoxib [27-32]. These encouraging results suggest that POD-loaded NLCs will exhibit enhanced therapeutic efficiency against CA.

In the present study, POD was loaded into NLCs to improve its skin targeting efficiency. Two kinds of POD-NLCs were prepared and characterized, and their skin targeting efficiencies were compared. A preliminary safety evaluation of POD-NLC exhibiting higher skin targeting efficiency was also conducted.

\section{Results and Discussion}

\subsection{Mean Particle Size, Polydispersity Index, and Zeta Potential}

The mean particle size of POD-NLC formulation $1_{1}$ and POD-NLC $C_{\text {formulation } 2}$ was $106 \mathrm{~nm}$ and $219 \mathrm{~nm}$, respectively. Both preparations have a relatively uniform particle size, as indicated by their small polydispersity indexes ( 0.211 for POD-NLC $\mathrm{formulation} 1_{1}$ and 0.221 for POD-NLC $\left.\mathrm{formulation} 2_{2}\right)$, and have similar zeta potentials ( $-18.00 \mathrm{mV}$ for POD-NLC formulation $1_{\text {and }}-16.4 \mathrm{mV}$ for POD-NLC $\mathrm{C}_{\text {formulation } 2}$ ).

\subsection{POD Loading and Entrapment Efficiency}

The POD content in both NLCs was relatively low (less than $0.5 \%$ ), though a slightly higher content of POD was seen in POD-NLC formulation $2_{2}(0.49 \%)$ compared to POD-NLC formulation $1_{1}(0.33 \%)$. Both NLCs also had high POD entrapment efficiencies (88.25\% for POD-NLC formulation $1_{1}$ and $93.50 \%$ for POD-NLC formulation 2). $_{\text {) }}$.

\subsection{Differential Scanning Calorimetry (DSC)}

The DSC thermograms for POD, Compritol ${ }^{\circledR} 888$ ATO, a physical mixture of POD and Compritol ${ }^{\circledR} 888 \mathrm{ATO}$, and lyophilized samples of blank $\mathrm{NLC}_{\text {formulation 1, }}$ POD-NLC $\mathrm{formulation} \mathrm{1,} \mathrm{and}_{\text {, }}$

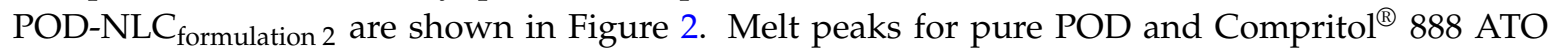
were observed at 186.0 and $73.5^{\circ} \mathrm{C}$, respectively. The corresponding melt peaks are 182.8 and $73.4{ }^{\circ} \mathrm{C}$ in their physical mixture, suggesting that the physical state of the drug and solid lipid were not affected by mixing. The slight difference in the melt temperatures of POD alone and POD in the physical mixture is probably due to measurement error. No melt peak was observed for POD in the thermograms of POD-loaded NLCs, indicating either complete solubilization of POD in the lipid matrix or transformation of POD crystal to an amorphous form that has been dispersed in the lipid matrix [33]. Compared with Compritol ${ }^{\circledR} 888$ ATO alone, the melt peak for Compritol ${ }^{\circledR} 888$ ATO was broadened and shifted to a lower temperature in blank and POD-loaded NLCs. The large surface area of nanoparticles and other excipients such as oil and surfactant may act as impurities that affect the melting point of Compritol ${ }^{\circledR} 888$ ATO [34].

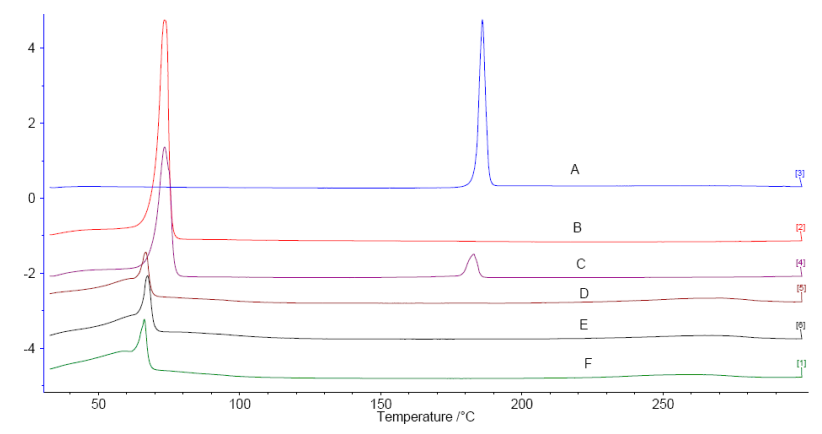

Figure 2. Differential Scanning Calorimetry (DSC) heating curves of podophyllotoxin-loaded

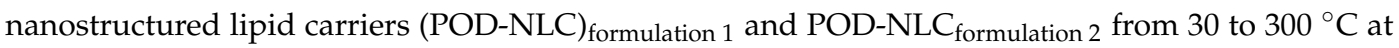
a heating rate of $10^{\circ} \mathrm{C} / \mathrm{min}$. A: POD; B: Compritol 888 ATO; C: Physical mixture of POD and Compritol

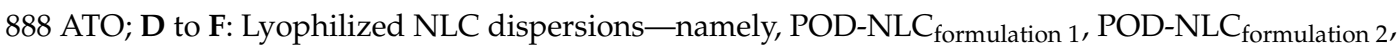

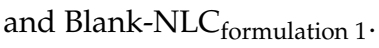




\subsection{In Vitro Release}

Cumulative in vitro release percentages of POD from NLCs are shown in Figure 3. POD was released slowly from both NLCs, and less than 10\% of loaded POD was released over a $12 \mathrm{~h}$

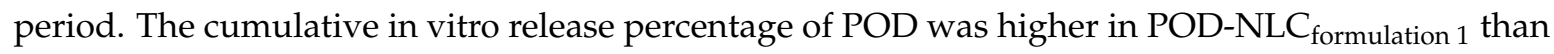

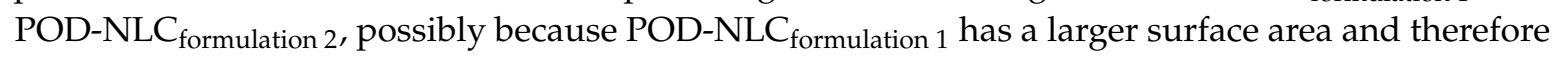
presents a larger contact area to the release medium.

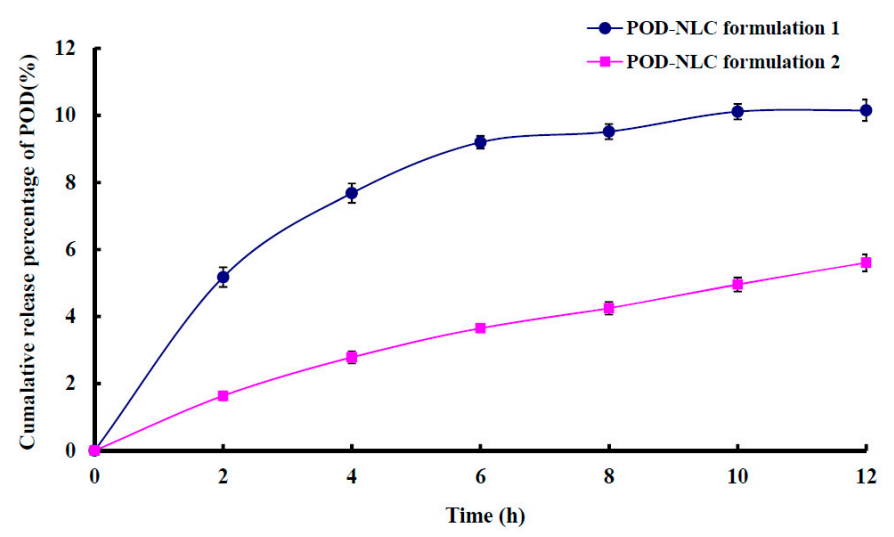

Figure 3. Cumulative in vitro release percentages of POD from POD-NLC $\mathrm{formulation}_{1}$ and POD-NLC $\mathrm{formulation} 2_{2}$ versus time profiles.

\subsection{In Vitro and In Vivo Skin Retention}

Figure 4 shows the in vitro and in vivo rat skin deposits of POD at $8 \mathrm{~h}$ after the application

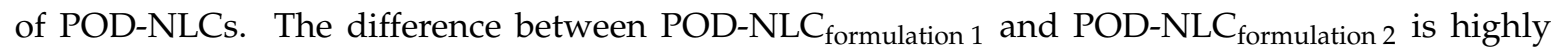

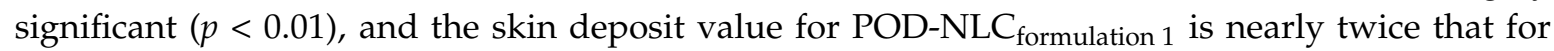

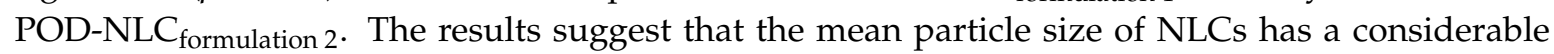
influence on the skin targeting efficiency of hydrophobic APIs loaded into them. A potential explanation is that lipid particles form an adhesive layer occluding the skin surface after water evaporates from the lipid nanodispersion [5]. As a consequence, hydration of the stratum corneum may increase and facilitate drug penetration into skin. The highest occlusivity will be achieved by NLCs containing the smallest particles [8].

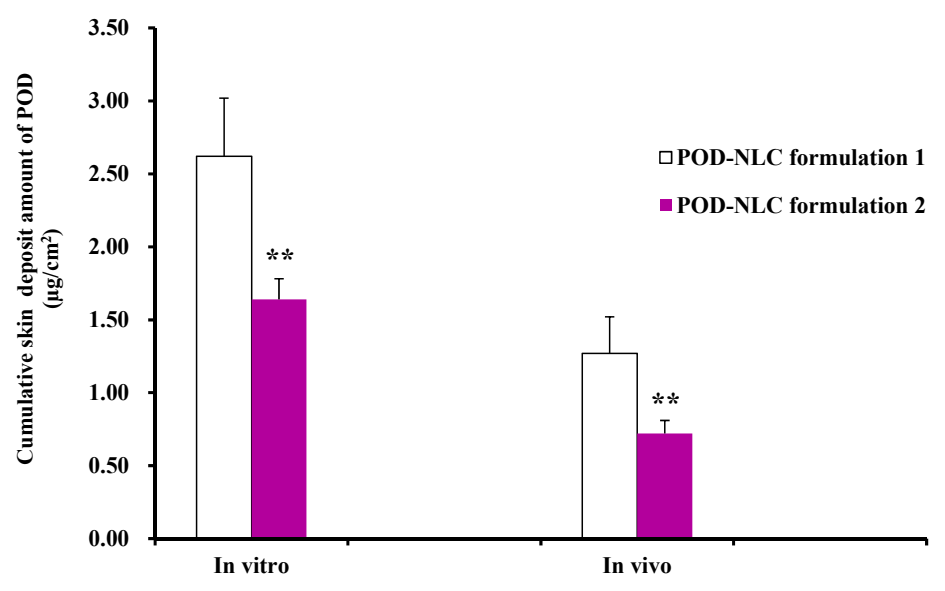

Figure 4. In vitro and in vivo rat skin deposit amounts of POD at $8 \mathrm{~h}$ after the topical treatment

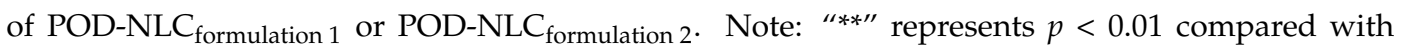

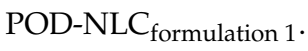




\subsection{Confocal Laser Scanning Microscopy (CLSM)}

To visualize the skin distribution behavior of hydrophobic active pharmaceutical ingredients (APIs) when NLCs were used as carriers, POD was replaced with Nile red (NR-a hydrophobic fluorescent probe), and the distribution behavior of $\mathrm{NR}^{-N L C} \mathrm{C}_{\text {formulation } 1}$ and NR-NLC $\mathrm{C}_{\text {formulation } 2}$ in rat skin in vivo was observed using confocal laser scanning microscopy (CLSM). The mean particle sizes of NR-NLC formulation 1 and NR-NLC formulation $2_{2}$ were $120 \mathrm{~nm}$ and $219 \mathrm{~nm}$, respectively. These results indicate that replacing POD with NR does not influence the particle size of the NLCs.

CLSM images of vertical slices of rat skin obtained $4 \mathrm{~h}$ after the application of NR-NLCs are shown in Figure 5. For both NLCs, NR is distributed primarily in the epidermal layer of the skin, indicative of high skin targeting efficiency. Our results are consistent with those reported previously [35-37]. By visual inspection, the fluorescence intensity of NR appears to be higher in the epidermal layer after the application of NR-NLC formulation $1_{\text {than that of NR-NLC }}$ formulation 2, suggesting that the NLC with the smaller mean particle size has higher epidermal targeting efficiency. This result is in accordance with results from the in vitro and in vivo skin retention experiments, and supports the conclusion that drugs loaded in NLCs are mainly targeted to the epidermal layer.

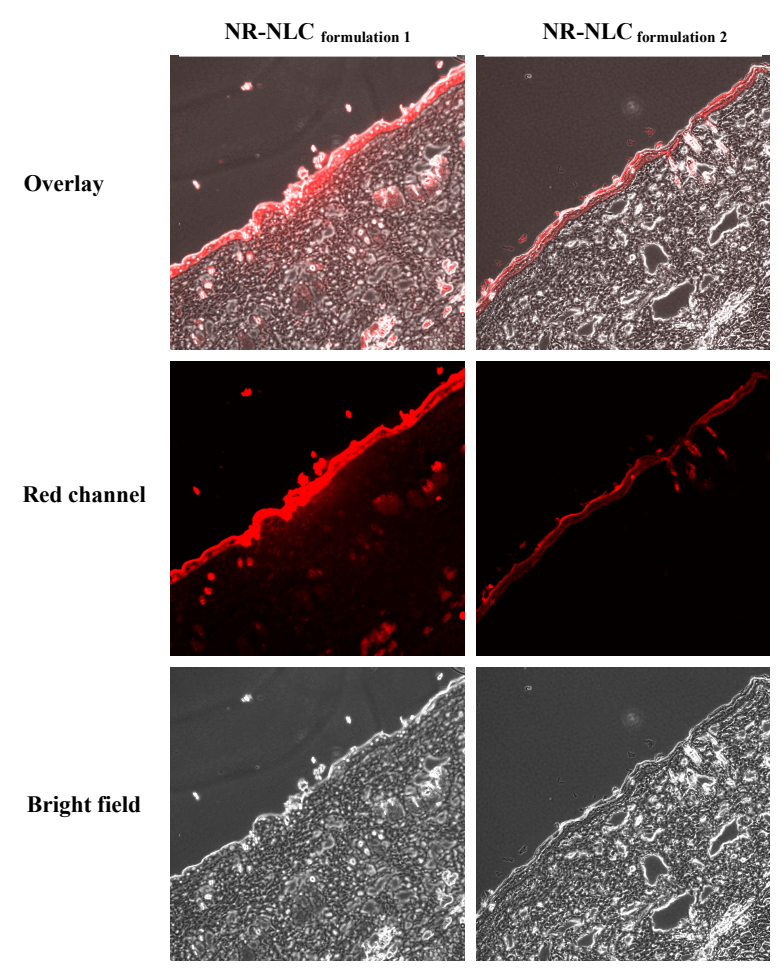

Figure 5. Confocal laser scanning microscopy (CLSM) images of vertical slices $(10 \mu \mathrm{m})$ of rat skin, $4 \mathrm{~h}$ after the administration of Nile red-loaded NLC (NR-NLC) formulation $1(109.7 \mathrm{~nm})$ and NR-NLC formulation $2(219.4 \mathrm{~nm})$.

\subsection{Skin Irritation Evaluation}

Representative images of intact or damaged rabbit skin before and after NLC treatment are shown in Figures 6 and 7. No irritation was observed after multiple-dose administration of

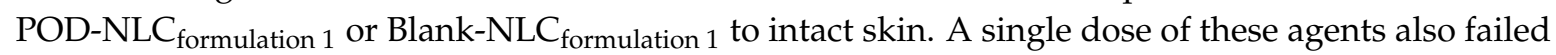
to irritate skin damaged by wounding. These promising results suggest that POD-NLC $\mathrm{C}_{\text {formulation } 1}$ can safely deliver POD. 


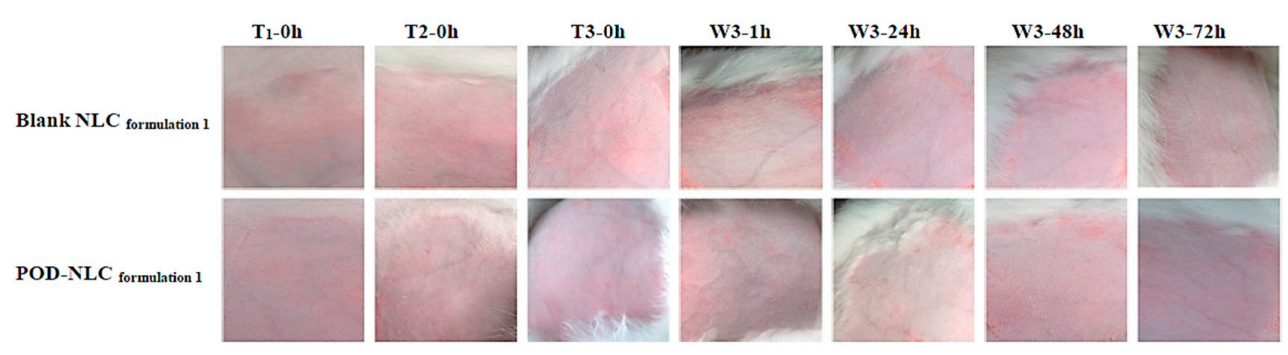

Figure 6. Images of intact rabbit skin before and after three times of topical administration of POD-NLC $\mathrm{formulation} 1_{1}$ or blank $\mathrm{NLC}_{\text {formulation } 1}$. Notes: $\mathrm{T}_{1}-0 \mathrm{~h}, \mathrm{~T}_{2}-0 \mathrm{~h}$ and $\mathrm{T}_{3}-0 \mathrm{~h}$ represent immediately before the first, second, and third times of administration; W3-1 h, W3-24 h, W3-48 h, and W3-72 h represent $1,24,48$, and $72 \mathrm{~h}$ after the washing off of the residual of the formulation after the last time of administration.

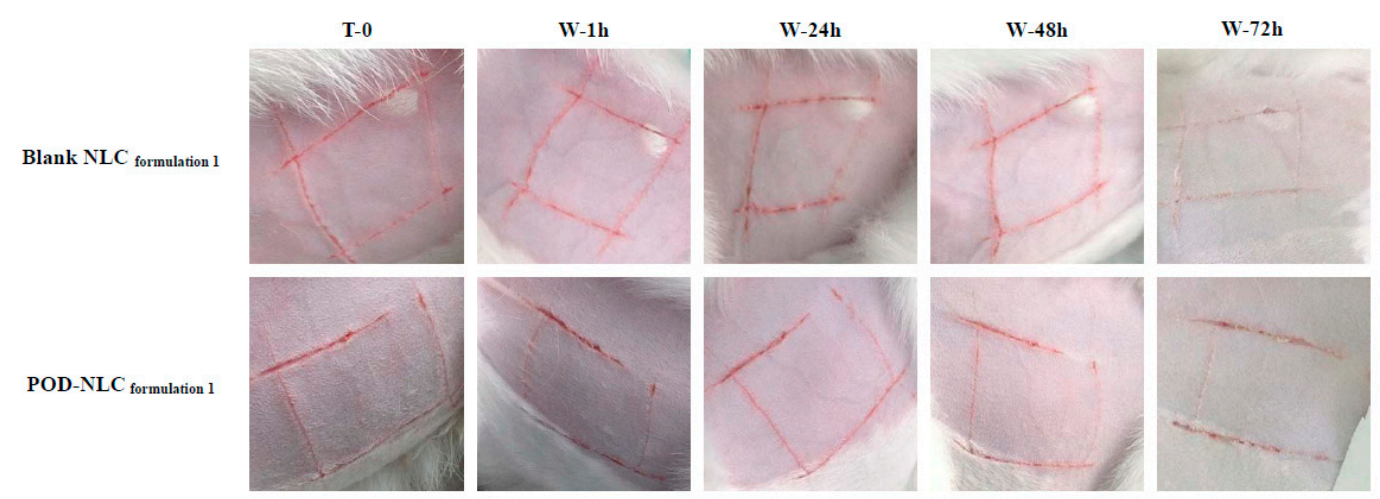

Figure 7. Images of damaged rabbit skin before and after the single-time topical administration

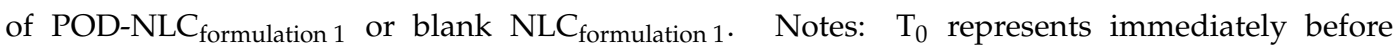
the administration; $\mathrm{W}-1 \mathrm{~h}, \mathrm{~W}-24 \mathrm{~h}, \mathrm{~W}-48 \mathrm{~h}$, and $\mathrm{W}-72 \mathrm{~h}$ represent $1,24,48$, and $72 \mathrm{~h}$ after the washing off of the residual of the formulation.

\section{Materials and Methods}

\subsection{Reagents}

Podophyllotoxin (POD) was obtained from HUAHAI Pharmaceutical Co., Ltd., Fujian, China. Cremophor ${ }^{\circledR}$ RH 40 (Polyoxyl 40 hydrogenated castor oil) was purchased from BASF SE, Ludwigshafen, Germany. Compritol ${ }^{\circledR} 888$ ATO (Glyceryl behenate) and Labrasol ${ }^{\circledR}$ (Caprylocaproyl macrogolglycerides) were provided by Gattefossè, Saint Priest, France. Soybean phosphatidylcholine (SPC) was purchased from Shanghai Taiwei Pharmaceutical Company Limited, Shanghai, China. Other chemicals were of HPLC or analytical grade.

\subsection{Preparation of Podophyllotoxin-Loaded Nanostructured Lipid Carriers}

Podophyllotoxin-loaded nanostructured lipid carriers were prepared by hot high pressure homogenization. Briefly, Compritol ${ }^{\circledR} 888 \mathrm{ATO}$ and Labrasol ${ }^{\circledR}$ were melted at $80{ }^{\circ} \mathrm{C}$ in a water bath. POD was dissolved in $5 \mathrm{~mL}$ dichloromethane, and the melted lipids were added. The organic solvent was removed by magnetic stirring at $800 \mathrm{rpm}$ for $15 \mathrm{~min}$ at room temperature, and the oil phase was then collected. To generate the aqueous phase, Cremophor RH40 ${ }^{\circledR}$ and SPC were dissolved in $100 \mathrm{~mL}$ of purified water at $80^{\circ} \mathrm{C}$ in a water bath, using magnetic stirring at $500 \mathrm{rpm}$ for $2 \mathrm{~min}$. The aqueous phase was added to the oil phase slowly using magnetic stirring at $500 \mathrm{rpm}$. The mixture was then stirred at $8000 \mathrm{rpm}$ for $10 \mathrm{~min}$ to obtain the pre-emulsion. Finally, the mixture was homogenized to obtain the dispersion of POD-NLC using nine cycles of pressurization at $600 \mathrm{bar}$ and cooling to $5{ }^{\circ} \mathrm{C}$. The formulations of POD-NLCs are shown in Table 1. 
Table 1. Formulation of POD-NLCs. PC: phosphatidylcholine.

\begin{tabular}{|c|c|c|}
\hline Drug and Excipients $(\mathrm{g} / 100 \mathrm{~mL})$ & POD-NLC formulation $1_{1}$ & POD-NLC formulation $2_{2}$ \\
\hline POD & 0.37 & 0.52 \\
\hline Compritol $^{\circledR} 888$ ATO & 4.30 & 10.0 \\
\hline Labrasol $^{\circledR}$ & 0.76 & 1.8 \\
\hline Cremophor ${ }^{\circledR}$ RH40 & 5.02 & 11.7 \\
\hline SPC & 2.51 & 5.85 \\
\hline
\end{tabular}

\subsection{Mean Particle Size, Polydispersity Index, and Zeta Potential}

The particle size distribution (mean particle size and polydispersity index) and zeta potential analysis of POD-NLCs were performed using a Malvern Nano ZS90 Zetasizer (Malvern Instruments Ltd., Worcestershire, UK). Samples were diluted 50-fold in purified water before measurement.

\subsection{POD Loading and Entrapment Efficiency}

The entrapment efficiencies (EE) of POD in POD-NLCs were measured using centrifugal ultrafiltration as previously described [38]. Briefly, a $0.5 \mathrm{~mL}$ sample of NLC dispersion was centrifuged at $8000 \mathrm{rpm}$ for $20 \mathrm{~min}$ in a centrifugal ultrafiltration tube (Molecular weight cutoff $10 \mathrm{kDa}$ ), and the filtrate was subjected to HPLC to determine free POD content $\left(\mathrm{W}_{\mathrm{f}}\right)$. An identical volume of NLC dispersion was dissolved in methanol and subjected to HPLC to determine total POD content $\left(\mathrm{W}_{\mathrm{t}}\right)$. EE and POD loading were calculated as follows:

$$
\begin{gathered}
\text { Entrapment efficiency }(\mathrm{EE})=\frac{\left(\mathrm{W}_{\mathrm{t}}-\mathrm{W}_{\mathrm{f}}\right)}{\mathrm{W}_{\mathrm{t}}} \times 100 \% \\
\text { Loading }=\frac{\left(\mathrm{W}_{\mathrm{t}}-\mathrm{W}_{\mathrm{f}}\right)}{\mathrm{W}_{\mathrm{n}}} \times 100 \%
\end{gathered}
$$

where $\mathrm{W}_{\mathrm{f}}$ is the amount of free POD, $\mathrm{W}_{\mathrm{t}}$ is the amount of total POD present in $0.5 \mathrm{~mL}$ of NLC dispersion, and $\mathrm{W}_{\mathrm{n}}$ is the volume of NLC dispersion $(0.5 \mathrm{~mL})$.

\subsection{Differential Scanning Calorimetry (DSC)}

Thermal analysis of POD, Compritol ${ }^{\circledR} 888$ ATO, the physical mixture of POD with Compritol ${ }^{\circledR} 888$ $\mathrm{ATO}$, and lyophilized samples of blank $\mathrm{NLC}_{\text {formulation 1, }}$ POD-NLC formulation1 and POD-NLC formulation 2 was performed using a NETZSCH 240 F1 Differential Scanning Calorimeter (NETZSCH Instrument Ltd., Selb/Bavaria, Germany). DSC was performed using 3 to $5 \mathrm{mg}$ samples. Heating curves were recorded in the range of 30 to $300{ }^{\circ} \mathrm{C}$ at a heating rate of $10{ }^{\circ} \mathrm{C} / \mathrm{min}$ under inert atmosphere $\left(\mathrm{N}_{2}, 8 \mathrm{~mL} / \mathrm{min}\right)$.

\subsection{In Vitro Release}

The release of POD-NLCs was examined in vitro using a Franz diffusion cell system. The effective penetration area and receptor compartment volume were $2.0 \mathrm{~cm}^{2}$ and $12.5 \mathrm{~cm}^{3}$, respectively. Nitrocellulose membrane filter (pore size $0.1 \mu \mathrm{m}$, Sartorius AG, Germany) were used as barriers. Donor compartments contained either $0.25 \mathrm{~mL}$ POD-NLC $\mathrm{formulation} 1_{1}$ or an identical volume of

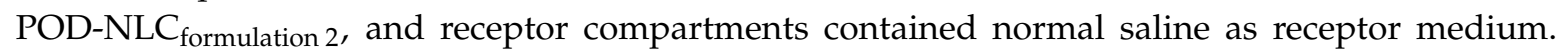
Receptor medium was maintained at $37^{\circ} \mathrm{C}$ in a water bath with magnetic stirring at $300 \mathrm{rpm}$ to ensure the uniform distribution of released POD. Samples of $0.5 \mathrm{~mL}$ were withdrawn from the receptor compartments at $0,2,4,6,8,10$, and $12 \mathrm{~h}$, and replaced with blank medium at the same volume at $37^{\circ} \mathrm{C}$. POD concentration was measured to determine cumulative release percentages by an HPLC method that we reported previously [39]. 


\subsection{In Vitro Skin Retention}

In vitro skin retention experiments were conducted using the in vitro release protocol, except the nitrocellulose membrane filter was replaced with freshly excised abdominal skin from male Sprague-Dawley rats, with the epidermal surface oriented towards the donor compartment. Eight hours after the application of POD-NLC formulation 1 $_{\text {or POD-NLC }}$ formulation 2, the skins $(n=5$ for each NLC formulation) were removed and rinsed with blank normal saline at $45^{\circ} \mathrm{C}$. A sample of $1 \mathrm{~cm}^{2}$ was taken from each harvested skin, cut into small pieces, and suspended in $0.5 \mathrm{~mL}$ normal saline. Each sample was homogenized in an ice bath and centrifuged at $5000 \mathrm{rpm}$ for $10 \mathrm{~min}$. The supernatant $(0.2 \mathrm{~mL})$ was extracted for $3 \mathrm{~min}$ in $0.6 \mathrm{~mL}$ ethyl acetate using a vortex mixer. After centrifugation at $5000 \mathrm{rpm}$ for $10 \mathrm{~min}$, the ethyl acetate layer was recovered and evaporated to dryness under a gentle nitrogen stream. The residue was reconstituted with $0.2 \mathrm{~mL}$ of methanol before POD level determination by the same HPLC method mentioned above.

\subsection{In Vivo Skin Retention}

Male Sprague-Dawley rats were anaesthetized with an intraperitoneal injection of urethane $(1.5 \mathrm{~g} / \mathrm{kg})$. After the abdominal fur was carefully removed with an electric clipper, rats were placed on heating pads maintained at $37 \pm 1{ }^{\circ} \mathrm{C}$. Then, $0.28 \mathrm{~mL}$ of POD-NLC $\mathrm{C}_{\text {formulation } 1}$ or POD-NLC $\mathrm{C}_{\text {formulation } 2}$ was applied to the abdominal skin $\left(2.3 \mathrm{~cm}^{2}\right)$ of each rat. The rats were kept in a dark room during the experiments to minimize POD photodegradation. After $8 \mathrm{~h}$, the animals were sacrificed $(n=3$ for each NLC formulation) and the treated skin excised. The tissue was wiped clean with a sponge soaked in blank normal saline at $45^{\circ} \mathrm{C}$, and then a sample of $1 \mathrm{~cm}^{2}$ was taken from each skin. Skin sample preparation and HPLC conditions were identical to those used in the in vitro experiments described above.

\subsection{Confocal Laser Scanning Microscopy (CLSM)}

To compare differences in skin distribution behavior exhibited by NLCs with different properties, POD was replaced with Nile red (NR, a commonly used fluorescent probe), and NR loaded NLCs were prepared. The characteristics of NR-NLC formulation $1_{1}$ and NR-NLC $\mathrm{formulation} 2_{2}$ are shown in Table 2. The mean particle size and polydispersity index (PDI) of NR-NLC $\mathrm{Cormulation} 1_{\text {or }}$ NR-NLC $\mathrm{C}_{\text {formulation } 2}$

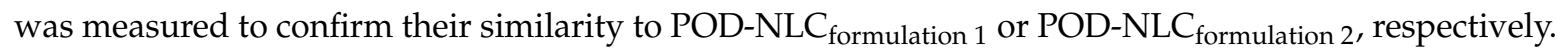

Table 2. Formulations of NR-NLCs.

\begin{tabular}{|c|c|c|}
\hline Drug and Excipients $(\mathrm{g} / 100 \mathrm{~mL})$ & NR-NLC formulation $1_{1}$ & NR-NLC $_{\text {formulation } 2}$ \\
\hline Nile red & 0.005 & 0.005 \\
\hline Compritol $^{\circledR} 888$ ATO & 3.54 & 8.2 \\
\hline Labrasol $^{\circledR}$ & 0.76 & 1.8 \\
\hline Cremophor ${ }^{\circledR}$ RH40 & 5.02 & 11.7 \\
\hline SPC & 2.51 & 5.85 \\
\hline
\end{tabular}

In vivo rat skin deposit experiments using NR-NLCs ( $n=3$ for each formulation) were conducted following the same procedures for POD-NLCs, except that the rats were sacrificed $4 \mathrm{~h}$ after administration instead of $8 \mathrm{~h}$. Excised skin was wiped clean with a sponge soaked in blank normal saline at $45^{\circ} \mathrm{C}$, and then $1 \mathrm{~cm}$ samples were embedded in optimal cutting temperature compound (OCT). Three vertical slices $(10 \mu \mathrm{m})$ of each sample were obtained using a Leica CM1850 cryostat (Leica Inc., Wetzlar, Germany). The distribution of the fluorescent marker was observed using an Olympus FluoView FV10i confocal microscope (Olympus, Tokyo, Japan). Skin slices were examined under both normal and UV (excitation at $559 \mathrm{~nm}$ ) light, and emission spectra were recorded from 570 to $670 \mathrm{~nm}$. CLSM images in bright-field and red channels were superimposed to visualize NR distribution. 


\subsection{Skin Irritation Evaluation}

The potential for POD-NLC formulation $1_{1}$ to irritate normal skin after multiple-dose administration was investigated according to OECD Guideline 404, "Acute Dermal Irritation/Corrosion" [40]. The effects of POD-NLC formulation $1_{1}$ on compromised skin after single-dose administration were also evaluated.

Eight New Zealand rabbits $(2.0-2.5 \mathrm{~kg})$ were randomly divided into normal and compromised skin groups ( $n=4$ in each group, half male and half female). A small region on both flanks of each rabbit (approximately $3 \times 3 \mathrm{~cm}$ ) was shaved with an electric clipper. Rabbits in the compromised skin group were wounded in a "\#"-shaped pattern on both flanks to induce staxis and were allowed $24 \mathrm{~h}$ to

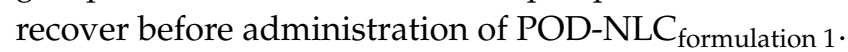

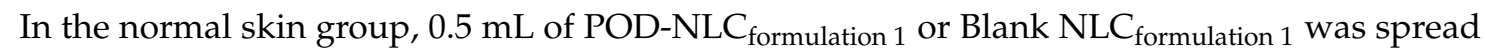
evenly onto a gauze patch (approximately $2.5 \times 2.5 \mathrm{~cm}$ ). Patches were applied to the left and right flank of each rabbit and secured with non-irritating elastic bandage. Patches were applied for four hours each day for three days. While the patches were in place, the rabbits were restrained. Treated regions were visually inspected and photographed before patches were applied and after they were removed. When a patch was removed, the area was swabbed with warm normal saline before observations were recorded. Rabbits in the compromised group received only one $4 \mathrm{~h}$ treatment with $0.5 \mathrm{~mL}$ of POD-NLC formulation 1 $_{\text {or Blank NLC }}$ formulation 1. Before patches were applied, and at 1, 24, 48, and $72 \mathrm{~h}$ after patches were removed, the treated areas on both flanks of each rabbit were observed for any evidence of erythema and edema and were photographed.

\section{Conclusions}

It has been widely reported that drugs exhibit high skin targeting efficiency when NLCs are used as vehicles for topical delivery. In this study, POD-loaded NLCs with smaller mean particle size exhibited higher skin targeting efficiency. Mean particle size might be an important parameter for formulation optimization when NLCs are used as carriers for hydrophobic APIs for topical application, considering that their loading is relatively low.

Acknowledgments: This work was supported by a grant (J50302) from the Shanghai Education Committee, Shanghai Natural Science Foundation Projects (10ZR1430100 and 11ZR1436500), the Shanghai Subject Chief Scientist Program (10XD14303900) from the Science and Technology Commission of Shanghai Municipality, and the Program for New Century Excellent Talents in Universities from the State Education Ministry, PR China (NCET08-0898), and the Program from Shanghai University of Traditional Chinese Medicine (No. 2015YSN09).

Author Contributions: Participated in research design: Nianping Feng, Jihui Zhao. Conducted experiments: Jihui Zhao, Xianghua Piao, Xiaoqin Shi. Performed data analysis: AiYong Si. Wrote or contributed to the writing of manuscript: Jihui Zhao, Yongtai Zhang, Nianping Feng.

Conflicts of Interest: The authors report no conflicts of interest in this work.

\section{References}

1. Mezei, M.; Gulasekharam, V. Liposomes-A selective drug delivery system for the topical route of administration. Lotion dosage form. Life Sci. 1980, 26, 1473-1477. [CrossRef]

2. Vermorken, A.J.; Hukkelhoven, M.W.; Vermeesch-Markslag, A.M.; Goos, C.M.; Wirtz, P.; Ziegenmeyer, J. The use of liposomes in the topical application of steroids. J. Pharm. Pharmacol. 1984, 36, 334-336. [CrossRef] [PubMed]

3. Mills, O.H., Jr.; Kligman, A.M. Treatment of acne vulgaris with topically applied erythromycin and tretinoin. Acta. Derm. Venereol. 1978, 58, 555-557. [PubMed]

4. Bangham, A.D.; Standish, M.M.; Watkins, J.C. Diffusion of univalent ions across the lamellae of swollen phospholipids. J. Mol. Biol. 1965, 13, 238-252. [CrossRef]

5. Schäfer-Korting, M.; Mehnert, W.; Korting, H.C. Lipid nanoparticles for improved topical application of drugs for skin diseases. Adv. Drug Deliv. Rev. 2007, 59, 427-443. [CrossRef] [PubMed] 
6. Pierre, M.B.; Dos Santos Miranda Costa, I. Liposomal systems as drug delivery vehicles for dermal and transdermal applications. Arch. Dermatol. Res. 2011, 303, 607-621. [CrossRef] [PubMed]

7. Moghimi, S.M.; Korting, H.C. Therapeutic progress with topical liposome for skin disease. Adv. Drug Deliv. Rev. 1996, 18, 335-342.

8. Müller, R.H.; Radtke, M.; Wissing, S.A. Solid lipid nanoparticles (SLN) and nanostructured lipid carriers (NLC) in cosmetic and dermatological preparations. Adv. Drug Deliv. Rev. 2002, 54 (Suppl. 1), S131-S155. [CrossRef]

9. Mehnert, W.; Mäder, K. Solid lipid nanoparticles: Production, characterization and applications. Adv. Drug Deliv. Rev. 2001, 47, 165-196. [CrossRef]

10. Liu, J.; Hu, W.; Chen, H.; Ni, Q.; Xu, H.; Yang, X. Isotretinoin-loaded solid lipid nanoparticles with skin targeting for topical delivery. Int. J. Pharm. 2007, 328, 191-195.

11. Jeon, H.S.; Seo, J.E.; Kim, M.S.; Kang, M.H.; Oh, D.H.; Jeon, S.O.; Jeong, S.H.; Choi, Y.W.; Lee, S. A retinyl palmitate-loaded solid lipid nanoparticle system: Effect of surface modification with dicetyl phosphate on skin permeation in vitro and anti-wrinkle effect in vivo. Int. J. Pharm. 2013, 452, 311-320. [CrossRef] [PubMed]

12. Santos Maia, C.; Mehnert, W.; Schaller, M.; Korting, H.C.; Gysler, A.; Haberland, A.; Schäfer-Korting, M. Drug targeting by solid lipid nanoparticles for dermal use. J. Drug Target. 2002, 10, 489-495. [CrossRef] [PubMed]

13. Pople, P.V.; Singh, K.K. Targeting tacrolimus to deeper layers of skin with improved safety for treatment of atopic dermatitis-Part II: In vivo assessment of dermatopharmacokinetics, biodistribution and efficacy. Int. J. Pharm. 2012, 434, 70-79. [CrossRef] [PubMed]

14. Lv, Q.; Yu, A.; Xi, Y.; Li, H.; Song, Z.; Cui, J.; Cao, F.; Zhai, G. Development and evaluation of penciclovir-loaded solid lipid nanoparticles for topical delivery. Int. J. Pharm. 2009, 372, 191-198. [CrossRef] [PubMed]

15. Souto, E.B.; Wissing, S.A.; Barbosa, C.M.; Müller, R.H. Development of a controlled release formulation based on SLN and NLC for topical clotrimazole delivery. Int. J. Pharm. 2004, 278, 71-77. [CrossRef] [PubMed]

16. Mitri, K.; Shegokar, R.; Gohla, S.; Anselmi, C.; Müller, R.H. Lipid nanocarriers for dermal delivery of lutein: Preparation, characterization, stability and performance. Int. J. Pharm. 2011, 414, 267-275. [CrossRef] [PubMed]

17. Tiyaboonchai, W.; Tungpradit, W.; Plianbangchang, P. Formulation and characterization of curcuminoids loaded solid lipid nanoparticles. Int. J. Pharm. 2007, 337, 299-306. [CrossRef] [PubMed]

18. Bose, S.; Du, Y.; Takhistov, P.; Michniak-Kohn, B. Formulation optimization and topical delivery of quercetin from solid lipid based nanosystems. Int. J. Pharm. 2013, 441, 56-66. [CrossRef] [PubMed]

19. Montenegro, L.; Sinico, C.; Castangia, I.; Carbone, C.; Puglisi, G. Idebenone-loaded solid lipid nanoparticles for drug delivery to the skin: In vitro evaluation. Int. J. Pharm. 2012, 434, 169-174. [CrossRef] [PubMed]

20. Dupin, N. Genital warts. Clin. Dermatol. 2004, 22, 481-486. [CrossRef] [PubMed]

21. Wang, J.-B.; Liu, Y.-H.; Li, S.-T. A clinical study on $0.5 \%$ podophyllotoxin tincture in treatment of condylomata acuminate. Chin. J. New Drugs 1996, 5, 125-127.

22. Cassidy, D.E.; Drewry, J.; Fanning, J.P. Podophyllum toxicity: A report of a fatal case and a review of the literature. J. Toxicol. Clin. Toxicol. 1982, 19, 35-44. [CrossRef] [PubMed]

23. Von Krogh, G. Podophyllotoxin in serum: Absorption subsequent to three-day repeated applications of a $0.5 \%$ ethanolic preparation on condylomata acuminata. Sex. Transm. Dis. 1982, 9, 26-33. [CrossRef] [PubMed]

24. Chen, H.; Chang, X.; Du, D.; Liu, W.; Liu, J.; Weng, T.; Yang, Y.; Xu, H.; Yang, X. Podophyllotoxin-loaded solid lipid nanoparticles for epidermal targeting. J. Control. Release 2006, 110, 296-306. [CrossRef] [PubMed]

25. Mehnert, W.; Mäder, K. Solid lipid nanoparticles: Production, characterization and applications. Adv. Drug Deliv. Rev. 2012, 64, S83-S101. [CrossRef]

26. Müller, R.H.; Petersen, R.D.; Hommoss, A.; Pardeike, J. Nanostructured lipid carriers (NLC) in cosmetic dermal products. Adv. Drug Deliv. Rev. 2007, 59, 522-530. [CrossRef] [PubMed]

27. Agrawal, Y.; Petkar, K.C.; Sawant, K.K. Development, evaluation and clinical studies of Acitretin loaded nanostructured lipid carriers for topical treatment of psoriasis. Int. J. Pharm. 2010, 401, 93-102. [CrossRef] [PubMed] 
28. Puglia, C.; Blasi, P.; Rizza, L.; Schoubben, A.; Bonina, F.; Rossi, C.; Ricci, M. Lipid nanoparticles for prolonged topical delivery: An in vitro and in vivo investigation. Int. J. Pharm. 2008, 357, 295-304. [CrossRef] [PubMed]

29. Ricci, M.; Puglia, C.; Bonina, F.; di Giovanni, C.; Giovagnoli, S.; Rossi, C. Evaluation of indomethacin percutaneous absorption from nanostructured lipid carriers (NLC): In vitro and in vivo studies. J. Pharm. Sci. 2005, 94, 1149-1159. [CrossRef] [PubMed]

30. Han, F.; Yin, R.; Che, X.; Yuan, J.; Cui, Y.; Yin, H.; Li, S. Nanostructured lipid carriers (NLC) based topical gel of flurbiprofen: Design, characterization and in vivo evaluation. Int. J. Pharm. 2012, 439, 349-357. [CrossRef] [PubMed]

31. Brugè, F.; Damiani, E.; Puglia, C.; Offerta, A.; Armeni, T.; Littarru, G.P.; Tiano, L. Nanostructured lipid carriers loaded with CoQ10: Effect on human dermal fibroblasts under normal and UVA-mediated oxidative conditions. Int. J. Pharm. 2013, 55, 348-356. [CrossRef] [PubMed]

32. Joshi, M.; Patravale, V. Nanostructured lipid carrier (NLC) based gel of celecoxib. Int. J. Pharm. 2008, 346, 124-132. [CrossRef] [PubMed]

33. Das, S.; Ng, W.K.; Tan, R.B. Are nanostructured lipid carriers (NLCs) better than solid lipid nanoparticles (SLNs): Development, characterizations and comparative evaluations of clotrimazole-loaded SLNs and NLCs? Eur. J. Pharm. Sci. 2012, 47, 139-151. [CrossRef] [PubMed]

34. Lee, S.G.; Jeong, J.H.; Kim, S.R.; Lee, K.M.; Ahn, B.K.; Kang, M.H.; Choi, Y.W. Topical formulation of retinyl retinoate employing nanostructured lipid carriers. J. Pharm. Investig. 2012, 42, 243-250. [CrossRef]

35. Pople, P.V.; Singh, K.K. Development and evaluation of colloidal modified nanolipid carrier: Application to topical delivery of tacrolimus, Part II-In vivo assessment, drug targeting, efficacy, and safety in treatment for atopic dermatitis. Eur. J. Pharm. Biopharm. 2013, 84, 72-83. [CrossRef] [PubMed]

36. Pople, P.V.; Singh, K.K. Targeting tacrolimus to deeper layers of skin with improved safety for treatment of atopic dermatitis. Int. J. Pharm. 2010, 398, 165-178. [CrossRef] [PubMed]

37. Lombardi Borgia, S.; Regehly, M.; Sivaramakrishnan, R.; Mehnert, W.; Korting, H.C.; Danker, K.; Röder, B.; Kramer, K.D.; Schäfer-Korting, M. Lipid nanoparticles for skin penetration enhancement-correlation to drug localization within the particle matrix as determined by fluorescence and parelectric spectroscopy. J. Control. Release 2005, 10, 151-163. [CrossRef] [PubMed]

38. Yu, Y.-Y.; Zhao, J.-H.; Feng, N.-P.; Weng, H.-T.; Zhang, Y.-T.; Shi, X.-Q. Study on the Stability of Podophyllotoxin Solution. J. Nanjing TCM Univ. 2011, 27, 80-82.

39. Hu, K.; Zhu, L.; Liang, H.; Hu, F.; Feng, J. Improved antitumor efficacy and reduced toxicity of liposomes containing bufadienolides. Arch. Pharm. Res. 2011, 34, 1487-1494. [CrossRef] [PubMed]

40. Ema, M.; Matsuda, A.; Kobayashi, N.; Naya, M.; Nakanishi, J. Evaluation of dermal and eye irritation and skin sensitization due to carbon nanotubes. Regul. Toxicol. Pharmacol. 2011, 61, 276-281. [CrossRef] [PubMed]

Sample Availability: Samples of the compounds (podophyllotoxin, etc.) are available from the authors.

(C) 2016 by the authors; licensee MDPI, Basel, Switzerland. This article is an open access article distributed under the terms and conditions of the Creative Commons Attribution (CC-BY) license (http://creativecommons.org/licenses/by/4.0/). 